\title{
Pregnancy-induced hypertension syndrome and cardiovascular risk
}

\author{
Ana Ciléia Pinto Teixeira Henriques ${ }^{1 *}$, Júlio César Garcia de alencar $^{2}$, Lívia Rocha de Miranda Pinto ${ }^{3}$, Rosa Maria Salani \\ Mota $^{4}$, Raimunda Hermelinda Maia Macena ${ }^{5}$, Helvécio Neves Feitosa ${ }^{6}$, Francisco Herlânio Costa Carvalho ${ }^{7}$ \\ ${ }^{1}$ Masters in Public Health, Federal University of Ceará and Lecturer at the metropolitan Faculty of Greater Fortaleza (Fametro), Fortaleza, CE, Brazil. \\ ${ }^{2}$ Medical Undergraduate Degree from the Federal University of Ceará, Fortaleza, CE, Brazil. \\ ${ }^{3}$ Medical Undergraduate Degree from the Federal University of Ceará, Fortaleza, CE, Brazil. \\ ${ }^{4}$ Doctorate in Collective Health, Federal University of Ceará, Fortaleza, CE, Brazil. \\ ${ }^{5}$ Adjunct Professor II of Physiotherapy, Federal University of Ceará, Fortaleza, CE Brazil. \\ ${ }^{6}$ Adjunct Professor at the Department of Maternal and Child Health, Medical School, Federal University of Ceará, Fortaleza, CE, Brazil. \\ ${ }^{7}$ Adjunct Professor at the Department of Maternal and Child Health and Adjunct Professor in the Masters program of Public Health, Department of Community Health, Federal University of Ceará, Fortaleza, CE, Brazil.
}

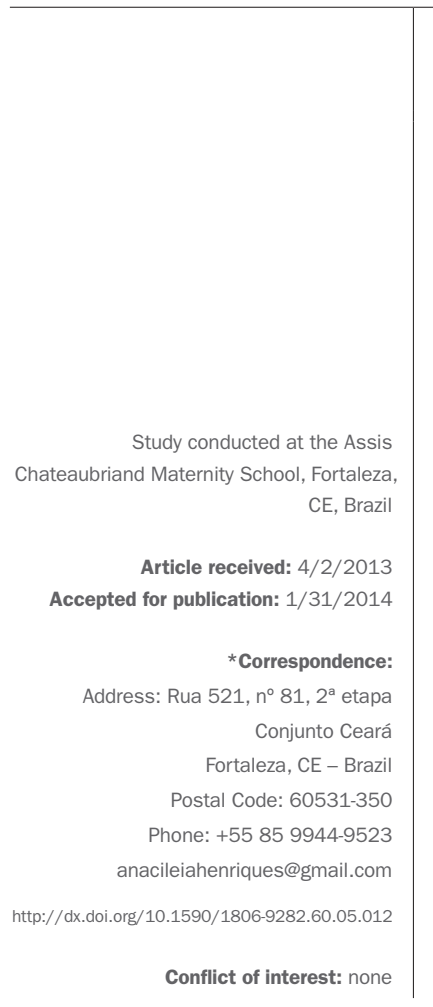

\section{SUMMARY}

Objective: to analyze the changes in life expectancy (LE) and disability-free life expectancy (DFLE) in São Paulo's elderly population to assess the occurrence of compression or expansion of morbidity, between 2000 and 2010.

Methods: cross-sectional and population survey, based on official data for the city of São Paulo, Brazil, and data obtained from the Health, Well-Being and Aging Survey (SABE). Functional disability was defined as difficulty in performing at least one basic activity of daily living. The Sullivan method was used to calculate LE and DFLE for the years 2000 to 2010.

Results: from 2000 to 2010, there was an increase in disabled life expectancy (DLE) in all age groups and both sexes. The proportion of years of life free of disability, at 60 years of age, decreased from $57.94 \%$ to $46.23 \%$ in women, and from $75.34 \%$ to $63.65 \%$ in men. At 75 years of age, this ratio decreased from $47.55 \%$ to $34.54 \%$ in women, and from $61.31 \%$ to $56.01 \%$ in men.

Conclusion: the expansion of morbidity is an ongoing process in the elderly population of the municipality of São Paulo, in the period 2000-2010. These results can contribute to the development of preventive strategies and planning of adequate health services to future generations of seniors.

Keywords: life expectancy, active life expectancy, life tables, morbidity, elderly.

\section{INTRODUCTION}

Cardiovascular diseases (CVD) are the leading cause of death in women and men in Brazil, accounting for about $20 \%$ of deaths in individuals over 30 years. ${ }^{1}$ The difference in mortality between genders was noticed since the mid 1980s and, since then, occurrence has increased among women. ${ }^{2}$

Certain conditions during pregnancy increase the risk of hypertension, diabetes and atherosclerosis, resulting in a higher chance of coronary heart disease in women at a young age. ${ }^{2}$ Among the pathological conditions that can compromise the normal course of pregnancy and have close relationship with these changes, the pregnancy-induced hypertension syndromes (PHS) are the entities most clinically relevant, being the leading cause of maternal and perinatal mortality in several studies in Brazil and worldwide. ${ }^{3,4}$
Recently, the relationship between the occurrence of a pregnancy complicated by hypertension and the development of future complications was assessed, focusing on cardiovascular disorders due to the magnitude and importance they tend to assume in the context of public health. ${ }^{5,6}$

The relationship between history of hypertension during pregnancy and the increased risk of CVD has been described in many studies whose results indicate PHS as a possible independent risk factor for cardiovascular disease, which deserves more attention when assessing the obstetric history of women, being even more important in the presence of traditional non-modifiable risk factors. ${ }^{6-8}$

This study sought to identify if the history of PHS is associated with changes in risk factors, morbidities and the occurrence of cardiovascular events (CVE), in the long 
run, characterizing the profile of cardiovascular risk (CVR) calculated according to the Framingham Score (FRS).

\section{Methods}

This is a retrospective cohort study involving 60 women who gave birth in the Assis Chateaubriand Maternity School-UFC (MEAC) between 1992 and 2002 (mean follow-up of 15.2 years). MEAC, located in Fortaleza, state of Ceará, is a tertiary hospital with specialized care in medium- and high-risk pregnancies, which treats patients from the state capital and countryside.

The sample size was calculated assuming the prevalence of HBP at $27 \%$ and mean odds ratio at 19.3 , according to a cohort study that assessed cardiovascular risk factors in women with history of pregnancy-induced hypertension syndrome, for a power of $90 \%$ and significance level at 5\%, resulting in a sample of 30 patients in each group. ${ }^{9}$

The group of exposed subjects comprised 30 women with any of the PHS classifications (three with chronic hypertension simultaneous to index pregnancy, two with pregnancy-induced hypertension, nine with mild preeclampsia, 13 with severe preeclampsia, two with preeclampsia superimposed on chronic hypertension, and one with eclampsia), and the group of non-exposed individuals included 30 women without pathological obstetric history, randomly selected in the same perinatal period of the patients included in EG. One non-exposed patient was selected for each exposed. For diagnosis and classification of PHS, the patients' medical records were checked. The classification considered was that on the day of hospital discharge and not on the day of admission.

At the time of selection, the participants who experienced any other obstetric complications during index pregnancy, specifically multiple gestation, and those related to placental disorders, such as premature placental detachment and placenta previa, were excluded, as well as those with conditions knowingly related with future cardiovascular risk, such as gestational diabetes. At the time of the risk assessment, those who were pregnant or in the postpartum period were excluded.

Patients selected in the first stage were invited for a clinical assessment via an invitation letter, home visit and/ or telephone contact explaining all of the objectives of the study, the exams to be conducted and emphasizing their freedom to accept participation in the study or otherwise, without damages or loss. If they agreed, and after signing the informed consent form, an assessment was scheduled for evaluation of current clinical and obstetri- cal variables, anthropometric assessment and laboratory assessment. The assessment of cardiovascular risks was conducted between March and September 2012.

The information collected in the medical records was checked with the patient and other up to date information was sought. Risk information before and after the index pregnancy was evaluated: age, race, parity, marital status, occupation, education level, family income, current obstetric history, smoking habits, current illnesses, practice of physical activity and family history of CVD (confounding variables), and also occurrence of CVE, current morbidity and use of medication (dependent variables).

Other dependent variables were assessed in the physical exam: measuring of systolic blood pressure (SBP) and diastolic blood pressure (DBP) with the use of the semiautomatic monitor Microlife BP 3BTO-H, according to the recommendations of the VI Brazilian Hypertension Guideline, ${ }^{10}$ weight and percentage of body fat assessments using a bioimpedance technique with the digital body analyzer scale Wiso W835, calculation of the Body Mass Index (BMI) in accordance with the Brazilian Obesity Guidelines 2009/2010, ${ }^{11}$ waist (WC), abdominal (AC) and hip circumference (HC) measurements for calculation of the following anthropometric ratios: waist to hip ratio (WHR), waist to height ratio (WHtR) and conicity index (C index), determined using the formula described by Valdez. ${ }^{12}$

Total cholesterol and fractions of HDL, LDL and VLDL, triglycerides, AST and ALT, urea and creatinine and fasting glucose were analyzed. Patients were advised to fast for 12 hours and abstain from alcohol one day before collecting blood. The Tinder enzymatic method was used to analyze the samples of total cholesterol and fractions and triglycerides, while the enzymatic method was used for the fasting glucose analysis, the Jaffe method for creatinine analysis and the UV kinetic method for evaluation of AST and ALT measurements.

The cardiovascular risk was also assessed using the Framingham Risk Score, given its globally recognized validity, using the variables of age, LDL-C, HDL-C, blood pressure, presence of diabetes and smoking habits. The risk of cardiovascular events occurring in 10 years is estimated using the total points for each factor. The revised Framingham Score for women was used. ${ }^{13}$

The data collected was tabulated and analyzed using the Statistical Package for Social Sciences for Personal Computer (SPSS-PC) software, version 18.0 with calculation of averages and standard deviations (SD) for analysis of the clinical and metabolic variables. The Kolmogo- 
rov-Smirnov test was used to test the normality of the variables, while the Student's t-test was used to compare the variables with the normal distribution, and the Mann-Whitney test for variables that were not normally distributed. Fisher's exact test was used for qualitative variables. Statistical significance was considered when the value of $\mathrm{p}<0.05$, with a confidence interval (CI) of $95 \%$. The odds ratio was calculated for the variables that were statistically significant in the first analysis.

The project was approved by the Research Ethics Committee/MEAC under Report no83/11.

\section{Results}

The groups did not differ in terms of age, parity, family history of CVD, race, smoking habits, physical activity or menopause.

Age at the time of delivery varied from 15 to 43 (average of $26.2 \pm 7.7$ ) years, and at the time of the risk assessment varied from 28 to 61 (average of $41.3 \pm 8.8$ ) years.

The patients did not differ in terms of prior obstetric history at index pregnancy in relation to the number of pregnancies $(2.2 \pm 2.3 \times 3.0 \pm 4.1 ; \mathrm{p}=0.78)$, parity $(1.0 \pm$
$1.9 \times 1.2 \pm 2.7, \mathrm{p}=0.26)$ and number of abortions $(0.2 \pm$ $0.4 \times 0.8 \pm 1.9 ; \mathrm{p}=0.25$ ).

The number of years in school varied between zero and eleven years $(6.9 \pm 3.1 \times 6.8 \pm 3.9 ; \mathrm{p}=0.91)$. Education level was not different between groups. Family income calculated using the number of minimum salaries varied between 0.5 and $3(1.5 \pm 0.6 \times 1.5 \pm 0.7 ; \mathrm{p}=1.00)$. Family income showed no difference between the groups, either.

Table 1 presents the current clinical history of the patients collected via anamnesis during a clinical visit.

The diagnosis of at least one morbid condition was informed by $40 \%$ of the women, showing a trend for a greater number of women with a diagnosis in the group of exposed patients.

High Blood Pressure (HBP) was the most frequent in both groups, having been cited by 15 (25\%) of patients in association with other pathologies or otherwise. Type 2 diabetes mellitus (DM) was the second most reported disease, with eight cases (13.3\%). Dyslipidemias also occupied a significant number of cited cases, accounting for $13.3 \%$ of cases.

TABLE 1 Current long-term medical history of women with (EG) and without pregnancy-induced hypertension (NEG). MEAC-UFC. Fortaleza, 2012

\begin{tabular}{|c|c|c|c|c|c|}
\hline & \multicolumn{4}{|c|}{ Exposure } & \multirow[b]{3}{*}{$\mathrm{P}^{*}$} \\
\hline & \multicolumn{2}{|c|}{ Non-exposed } & \multicolumn{2}{|c|}{ Exposed } & \\
\hline & $\mathrm{n}$ & $\%$ & $\mathrm{n}$ & $\%$ & \\
\hline Current diseases diagnosed/undergoing treatment & 8 & 26.7 & 16 & 53.3 & $0.06^{*}$ \\
\hline \multicolumn{6}{|l|}{ Disease classification** } \\
\hline $\mathrm{HBP}$ & 2 & 6.7 & 13 & 43.3 & - \\
\hline $\mathrm{DM}$ & 1 & 3.3 & 7 & 23.3 & \\
\hline Dyslipidemias & 2 & 6.7 & 6 & 20 & \\
\hline Occurrence of admissions & 9 & 30 & 9 & 30 & $1.00 *$ \\
\hline Occurrence of CVE*** & - & - & 3 & 10 & $0.23 * *$ \\
\hline Family history of CVD/CVE** & 25 & 86.2 & 29 & 96.7 & $0.19 * *$ \\
\hline \multicolumn{6}{|l|}{ Classification of the family history of CVD/CVE** } \\
\hline $\mathrm{HBP}$ & 22 & 75.8 & 21 & 70 & - \\
\hline DM & 7 & 24.1 & 14 & 46.6 & \\
\hline AMI & 4 & 13.8 & 7 & 23.3 & \\
\hline Stroke & 5 & 17.2 & 7 & 23.3 & \\
\hline \multicolumn{6}{|l|}{ Use of medication } \\
\hline Antihypertensive & 3 & 10 & 11 & 36.7 & $0.03 * *$ \\
\hline Hypoglycemic & 1 & 3.3 & 7 & 23.3 & $0.05 * *$ \\
\hline Anticoagulant & 1 & 3.3 & 2 & 6.7 & $1.00 * *$ \\
\hline Fibrates/statins & 1 & 3.3 & 4 & 13.3 & $0.35^{* *}$ \\
\hline Hormonal contraceptives & 1 & 3.3 & 4 & 13.3 & $0.35 * *$ \\
\hline
\end{tabular}

* Different statistical tests were used in the analysis: * $X^{2}$ test; **Fisher's test.

** The patients cited one or more pathologies.

*** HBP: high blood pressure; DM: diabetes mellitus; AMI: acute myocardial infarction; CHF: congestive heart failure; CVE: cardiovascular event; CVD: cardiovascular disease. 
In relation to the occurrence of cardiovascular events, three cases were documented among the 60 patients assessed (5\%), all of which occurred in patients from the exposed group. In relation to the classification, the occurrence of one case of deep vein thrombosis was reported, and two cases of cerebrovascular accidents. There was no statistically significant difference between the groups in relation to the occurrence of CVE.

After taking history of medication use by patients, we found a statistically significant difference in the use of antihypertensive and hypoglycemic medication, with a trend towards a difference between the groups. These medicines are used to treat the illnesses cited most by the patients in the study, with $23.3 \%$ of the sample reporting the use of an- tihypertensive medication and $13.3 \%$, the use of hypoglycemic medication. The OR was calculated for the use of antihypertensive medication, with a score of 5.2 (95CI: 1.3-21.2).

Table 2 presents the clinical and metabolic variables related to an unfavorable cardiovascular profile, with averages and standard deviations for each group.

The weight of the patients analyzed varied between 45 and $99.9 \mathrm{~kg}$ with a mean of $70.4 \pm 12.5 \mathrm{~kg}$, and no statistically significant difference between the patients.

The BMI assessment showed a statistically significant difference between the groups, with values between 19.7 and $46.9 \mathrm{~kg} / \mathrm{m}^{2}$ and a mean of $29.9 \pm 4.9$. The highest BMI values were found in the exposed group. The OR calculation was 1.13 (95CI: 1.00-1.3).

TABLE 2 Long-term clinical and metabolic characterization of women with (EG) and without pregnancy-induced hypertension (NEG). MEAC-UFC. Fortaleza, 2012

\begin{tabular}{|c|c|c|c|}
\hline \multirow[t]{2}{*}{ Clinical and metabolic characteristics } & \multicolumn{2}{|l|}{ Exposition } & \multirow[b]{2}{*}{$\mathbf{p}^{*}$} \\
\hline & Non-exposed & Exposed & \\
\hline \multicolumn{4}{|l|}{ Anthropometric variables } \\
\hline Weight (kg) & $68.6 \pm 9.5$ & $72.3 \pm 14.8$ & $0.25 *$ \\
\hline Height (m) & $1.54 \pm 0.1$ & $1.52 \pm 0.1$ & $0.06^{*}$ \\
\hline $\mathrm{BMI}\left(\mathrm{kg} / \mathrm{m}^{2}\right)$ & $28.5 \pm 3.2$ & $31.2 \pm 5.9$ & $0.03 *$ \\
\hline $\mathrm{SBP}(\mathrm{mmHg})$ & $119.4 \pm 14.3$ & $129.9 \pm 22.1$ & $0.03 *$ \\
\hline $\mathrm{DBP}(\mathrm{mmHg})$ & $78.9 \pm 11.3$ & $83.5 \pm 15.0$ & $0.19 *$ \\
\hline $\mathrm{AC}(\mathrm{cm})$ & $93.1 \pm 9.8$ & $97.2 \pm 12.4$ & $0.16^{*}$ \\
\hline WC $(\mathrm{cm})$ & $86.5 \pm 8.6$ & $89.1 \pm 11.8$ & $0.32 *$ \\
\hline $\mathrm{HC}(\mathrm{cm})$ & $102.7 \pm 8.3$ & $106.9 \pm 11.1$ & $0.10^{*}$ \\
\hline WHR & $0.8 \pm 0.1$ & $0.8 \pm 0.1$ & $0.63 *$ \\
\hline CIndex & $1.2 \pm 0.1$ & $1.2 \pm 0.1$ & $0.84^{*}$ \\
\hline WHtR & $0.6 \pm 0.1$ & $0.6 \pm 0.1$ & $0.12^{*}$ \\
\hline Biceps skin fold (mm) & $13.1 \pm 5.3$ & $15.6 \pm 8.7$ & $0.19 *$ \\
\hline Body fat (\%) & $42.9 \pm 6.1$ & $42.4 \pm 7.5$ & $0.75^{*}$ \\
\hline \multicolumn{4}{|l|}{ Metabolic variables } \\
\hline Total cholesterol & $177.6 \pm 40.1$ & $191.6 \pm 30.8$ & $0.13^{*}$ \\
\hline Triglycerides & $143.4 \pm 97.5$ & $155.1 \pm 73.3$ & $0.60^{*}$ \\
\hline LDL-c cholesterol & $104.7 \pm 31.4$ & $124.0 \pm 28.4$ & $0.02 *$ \\
\hline HDL-c cholesterol & $42.2 \pm 11.1$ & $39.9 \pm 10$ & $0.40^{*}$ \\
\hline VLDL-c cholesterol & $28.2 \pm 20.1$ & $30.2 \pm 12.9$ & $0.66^{*}$ \\
\hline AST & $35.6 \pm 14.2$ & $28.2 \pm 6.9$ & $0.01 *$ \\
\hline ALT & $30.2 \pm 15.2$ & $23.8 \pm 7.9$ & $0.06^{*}$ \\
\hline Urea & $25.1 \pm 7.4$ & $22.4 \pm 6.5$ & $0.16^{*}$ \\
\hline Creatinine & $0.7 \pm 0.1$ & $0.8 \pm 0.3$ & $0.17^{*}$ \\
\hline Fasting glucose & $96.5 \pm 9.9$ & $121.1 \pm 59.3$ & $0.02 * *$ \\
\hline
\end{tabular}

*Different statistical tests were used in the analysis: *Student' t-test; **Mann-Whitney.

BMI - Body Mass Index; SBP - systolic blood pressure; DBP - diastolic blood pressure; AC - abdominal circumference; WC - waist circumference; HC - hip circumference; WHR - waist to hip ratio; C Index - conicity index; WHtR - waist to height ratio; LDL-c - Low Density Lipid; HDL-c - High Density Lipoprotein; VLDL-c - Very Low Density Lipoprotein; AST - aspartate transaminase; ALT - alanine aminotransferase. 
SBP was also shown to be significantly different between the groups, with values between 88 and 192 $\mathrm{mmHg}$ and a mean of $124.6 \pm 19.1 \mathrm{mmHg}$. The patients in the exposed group presented higher average SBP values. The OR calculation was 1.03 (95CI: 1.00-1.06).

DBP varied between 56 and $111 \mathrm{mmHg}$, with a mean of $81.2 \pm 13.3 \mathrm{mmHg}$, and no statistically significant difference between the groups.

The waist (WC), abdomen (AC) and hip circumference (HC) measurements were taken. The WC measurements varied between 64 and $115 \mathrm{~cm}$ and presented a mean of $87.8 \pm 10.3 \mathrm{~cm}$. The AC measurements varied between 69 and $119 \mathrm{~cm}$, with a mean of $95.2 \pm 11.2 \mathrm{~cm}$. The HC measurements varied between 82 and $133 \mathrm{~cm}$, with a mean of $104.7 \pm 9.9 \mathrm{~cm}$. None of these presented a statistically significant difference between groups.

The following anthropometric ratios were calculated: waist to hip ratio (WHR), C Index and waist to height ratio (WHtR), with WHR values found varying between 0.70 and 0.97 with a mean of $0.8 \pm 0.1$ in the sample. The C Index varied between 1.00 and 1.39 , with a mean of $1.2 \pm 0.1$. The WHtR presented a greater variation between the groups, varying between 0.42 and $0.79 \mathrm{~m}$ with a mean of $0.6 \pm 0.1$.There was no significant difference for the three parameters analyzed above.

There were statistically significant differences for the values of the LDL portion of the cholesterol and fasting glucose, with higher values in the group of exposed patients. The LDL-c measurement varied between 50.2 and $189 \mathrm{mg} / \mathrm{dL}$ with a mean of $113.5 \pm 31.3$. Fasting glucose varied between 75 and $339 \mathrm{mg} / \mathrm{dL}$ with a mean of 108.8 \pm 43 .9. An OR for LDL-c of 1.02 was found (95CI: 1.00-1.04) while for fasting glucose the OR was 1.03 (95CI: 1.00-1.07).

The total cholesterol values found in the sample varied between 115 and $276 \mathrm{mg} / \mathrm{dL}$, with a mean of 184.5 $\pm 36.1 \mathrm{mg} / \mathrm{dL}$. The triglyceride values varied between 32 and $413 \mathrm{mg} / \mathrm{dL}$ with a mean of $149.3 \pm 85.7 \mathrm{mg} / \mathrm{dL}$ while the HDL-c varied between 25 and $70 \mathrm{mg} / \mathrm{dL}$ with a mean of $41.1 \pm 10.6 \mathrm{mg} / \mathrm{dL}$. There was no significant difference for the three parameters analyzed above.

The Framingham Risk Score was used for the cardiovascular risk assessment, estimating the risk of cardiovascular events in 10 years. Table 3 presents the scores relating to the Framingham Score calculation and the high and low risk categorization based on this score.

The Framingham Score varied in relation to scores with values between -7 and 22 with an average of $5.5 \pm 6.6$. The OR for the Framingham Score was 1.09 (95CI: 1.00-1.19).

Three patients (5\%) presented high cardiovascular risk, all in the exposed group; however, this variable was not statistically significant between the groups. When the frequency of low risk classification for CVE, characterized as a risk of less than $10 \%$, was analyzed a statistically significant difference was found between the groups, with all of the patients from the non-exposed group included in this classification. Only two patients were classified as having an intermediate risk (3.3\%), characterized as a risk between 10 and $20 \%$.

\section{Discussion}

The groups of patients analyzed were similar in terms of baseline characteristics in the period they started being monitored in relation to age, number of pregnancies, parity, abortions and smoking habits, factors which could cause a differentiated cardiovascular risk for age and smoking status are factors that affect the risk of CVE. Results of current studies present a differentiated cardiovascular profile for multiparous women and women with a history of consecutive abortions. ${ }^{14,15}$

In relation to current clinical history, the groups showed differentiated profiles for morbidity and use of medication, with the group of exposed patients holding a more unfavorable morbidity profile when compared to the non-exposed group.

Hypertension assumes a prominent role among the group of morbidities stated, with a frequency higher than expected for the general population found in this study.

TABLE 3 Long-term characterization of cardiovascular risk using the Framingham Score in women with (EG) and without pregnancy-induced hypertension (NEG). MEAC-UFC. Fortaleza, 2012

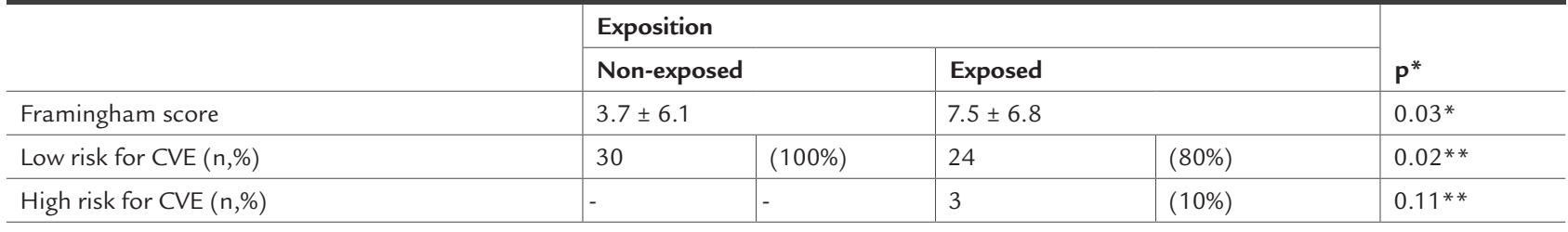

*Different statistical tests were used in the analysis: *Student' t-test; **Fisher's test. CVE - cardiovascular event; CVR - cardiovascular risk. 
One study found a prevalence of $22.7 \%$ for HBP, a lower value than that presented in our study. ${ }^{16}$

One study found that among 191 analyzed women with a history of PHS, $32.5 \%$ were hypertensive 21 years after the birth, a lower result than that found in this study, which presented a frequency of $43.3 \%$ in the group of exposed patients. ${ }^{17}$

The study found different relative risks for occurrence of HBP in women with a history of PHS depending on its seriousness. For women with a history of pregnancy-induced hypertension syndrome (PHS), the RR was found to be 2.47 while for preeclampsia/eclampsia (PE/E) the RR was 3.89?

The frequency of DM and dyslipidemias in treatment was also shown to be important in our study, with two conditions reported by $13.3 \%$ of patients. In the group of exposed patients, DM was reported by $23.3 \%$, a high frequency considering that presented in a national study, with a prevalence of $3.7 \%$ for diabetes mellitus. ${ }^{16}$

Analyzing the association between hypertensive disorders and the risk of maternal cardiovascular morbidity and type- 2 diabetes after follow-up for an average of 14.6 years, one study found that women with pregnancy-induced hypertension presented a risk 3.12 times higher for type $2 \mathrm{DM}$ diagnosis, and in those with PE the risk was 3.68 times higher. $^{6}$

The use of medication was also statistically significant when comparing the history of women with PHS and without exposure, but with a less striking risk gradient than that observed for the occurrence of hypertension. Women with a history of PHS presented RR of 1.89 and women with a history of PE/E had an RR of 1.90 for the use of medication. ${ }^{7}$

The literature is vast in pointing out that women with a history of PHS tend to present greater frequencies of hypertension and DM diagnoses and the use of antihypertensive and hypoglycemic medications. ${ }^{6,7,18}$

The small number of cases of CVE did not enable a significant different to be found between the groups, but draws attention to the fact that all cases found occurred in patients with a history of PHS.

Various studies evaluating CVE such as outcomes of the follow-ups of women with a history of PHS indicate a higher frequency of such events in this group. ${ }^{6,18,19}$

The practice of physical exercise was not shown to be different between the groups, with a low frequency of physical activity found in the sample studied. These results are comparable with the study which verified that the majority of women interviewed (68\%) did not practice physical activity. ${ }^{20}$
In relation to the clinical and metabolic assessment of the patients, important differences were found, which are significant to assessing the cardiovascular risk profile, the main objective of the assessment. The BMI was found to be significantly different in women with a history of PHS, data which has already been presented in other studies. ${ }^{5,21}$

A study that analyzed 40 women with a history of PHS and 14 with a history of normotensive pregnancies, after a follow-up period of 14.6 years in the exposed group and 15.9 years in the non-exposed group, found higher BMI, AC and DBP values in women with a history of PHS, with a mean BMI of $29.96 \pm 6.13 \mathrm{~kg} / \mathrm{m}^{2}$, AC of $93.15 \pm$ $12.31 \mathrm{~cm}$ and DBP of $82 \pm 11.86 \mathrm{mmHg}$ in the exposed group $\left(\mathrm{p}=0.019,0.026\right.$ and 0.047 , respectively). ${ }^{5}$

In our study, the mean BMI measurements in the two groups were higher than those found in this study ${ }^{5}$, demonstrating an even more unfavorable profile in this sample in relation to excess weight/obesity, which was found in $90 \%$ of the sample, drawing attention to the fact that class 2 and 3 obesity were only found in patients with a history of PHS. Another study found a prevalence of $47.7 \%$ for excess weight and obesity in women from São Leopoldo, state of Rio Grande do Sul (Brazil). ${ }^{16}$

Studies indicate that excess weight and obesity represent a serious health risk and are strongly associated with an increased risk of cardiovascular diseases, type 2 diabetes mellitus and metabolic disorders. ${ }^{22}$

One study that evaluated 168 pairs of women recruited between 1989 and 1997, 7.8 years after delivery, 105 of which had a history of PHS and 63 with a history of $\mathrm{PE}$, found higher average $\mathrm{BP}$ in patients with a history of PHS, with mean SBP values equal to $115 \mathrm{mmHg}$, lower than those presented by the patients in this study (129, $\pm 22.1 \mathrm{mmHg})^{21}$

Fraser et al. ${ }^{23}$ found that approximately 20 years after pregnancy, women with a history of PHS or PE presented higher BMI, WC and BP when compared with women with a history of normotensive pregnancies. The authors also found altered pressure values upon the birth of SGA infants.

The $\mathrm{AB}$ and $\mathrm{WC}$ measurements, important parameters in the evaluation of central obesity ${ }^{24}$ had higher means than the value considered appropriate according to national consensuses; however, this difference was not significant between groups. ${ }^{11,25}$

The accumulation of fat in women in the region of the trunk and abdomen is related to changes occurring in recent decades relating to dietary and lifestyle habits, which could indicate an increasingly higher exposure to cardiovascular risks. ${ }^{24}$ 
In addition to isolated anthropometric measurements, three important anthropometric ratios were analyzed (WHR, C Index and WHtR) already described in the literature in relation to their effectiveness in identifying the differentiated cardiovascular risk profile..$^{24,26,27}$

In this study, none of the ratios showed difference between the groups evaluated, with only the $\mathrm{C}$ Index and WHtR displaying higher values than recommended as cut-off points for the assessment of cardiovascular risk in women. ${ }^{26,27}$

Analyzing the blood chemistry characteristics, an unfavorable lipid profile was found in the exposed sample, where the measurements of LDL cholesterol were higher, which is concerning given that this portion of cholesterol is related with an unfavorable cardiovascular risk profile in the general population. The study found lower average LDL-c in the sample studied (120.7 \pm 33.2$)$, with no statistically significant difference between the groups in relation to this measurement. ${ }^{5}$

The measurements of the average total cholesterol, triglycerides and VLDL were higher in the exposed group; nevertheless, the differences were not found to be statistically significant, unlike the results of other studies showing a completely altered lipid profile in patients with a history of PHS. ${ }^{21}$ The small sample may have been responsible for the lack of statistical significance in relation to these values.

In both groups, the mean values for HDL-c portion were lower than the value recommended by national consensuses as ideal parameters for the female population, being the second most altered measurement in the sample studied (75.9\%). The fraction of HDL cholesterol includes actions that contribute to protection of the vascular bed against atherogenesis, such as the removal of oxidized lipids in LDL, inhibition of attachment of adhesion molecules and monocytes to the endothelium and stimulation of nitric oxide release. Therefore the reduction in the levels of this portion of cholesterol, an abnormality demonstrated in other studies, is troublesome. ${ }^{28}$

The difference in fasting glucose was statistically significant, with exposed patients presenting the highest averages. When analyzed for their adequacy in terms of the parameters considered as normal for evaluation of diabetes, all patients with values above that recommended by the Brazilian Diabetes Society, ${ }^{11}$ i.e., $126 \mathrm{mg} / \mathrm{dL}$, were allocated to the exposed group.

Regarding the cardiovascular risk profile calculated using FRS, the study showed that $16 \%$ of women with a history of PHS had Framingham risk scores 30\% higher than women with a history of normotensive pregnancies, even after adjustment for pre-pregnancy BMI. The authors believe that the explanation for the entire cohort being assessed as a low risk profile for CVE resides in the young age of the patients in the study, having found an average risk of $3 \%$, with evidence of variations related to complications during pregnancy. ${ }^{23}$

In this study, we only found five patients in the sample $(8.5 \%)$ with an unfavorable cardiovascular risk profile according to the Framingham Score. Even in small numbers, the occurrence of an unfavorable risk profile for CVE (intermediate or high) in the exposed group indicates the need for research with larger samples in these groups, temporally assessing the modification of this risk according to exposure.

The body of evidence published so far demonstrates the need for a differentiated clinical attention for patients with a history of PHS, encouraging more specific and earlier reviews in this group of patients, with postpartum and long-term follow-up focusing on the prevention of cardiovascular events.

Despite the clear association with an increased risk in patients with a history of PHS, due to the similarity between the groups regarding other risk factors for CVD, the findings should be interpreted with caution. The number of patients can be considered small. It was difficult to find many of the patients owing to changes of address and phone numbers, and a considerable number refused to participate. Although random, there may have been a selection of cases very similar to the controls, which may also have contributed to the identification of few differences for the risk assessments.

The analysis was able to provide a relatively long follow up, which should be considered very positive. However, follow up times with longer monitoring periods are needed, especially after the implementation of protective measures to investigate whether the risk can be modified or be considered as unchanging, similar to a family history of CVD. That is, there is still doubt as to whether PHS is an event associated with increased risk of CVE alone or if this increased risk is only associated with other factors that it causes: increased central obesity, metabolic syndrome, hyperglycemia, and hypertension.

Further investigations should be made into the relationship between the severity of PHS and its recurrence with the severity of interference in cardiovascular risk, and the association with other sexual and reproductive factors, inclu- 
ding isolated and joint adverse perinatal outcomes. The ideal would be to assess the real value of each obstetric factor (e.g. prematurity, low birth weight and fetal growth restriction) on the risk of the development of future CVE.

\section{Conclusion}

The study showed an unfavorable cardiovascular risk profile in patients with a history of PHS, demonstrated through changes in anthropometric measurements such as BMI and WC, as well as metabolic measurements, such as the lipid profile (LDL-c cholesterol), and glycemic measurements (fasting glucose), even in patients considered young for the prevalence of such conditions. The patients in the exposed group presented higher Framingham Risk Scores.

\section{Resumo}

Síndrome hipertensiva gestacional e risco cardiovascular.

Objetivo: caracterizar o perfil de risco cardiovascular em longo prazo de mulheres com história de síndrome hipertensiva da gestação (SHG) e compará-lo ao de mulheres com histórico de gestação normotensa.

Métodos: este é um estudo de coorte retrospectivo que incluiu 60 mulheres que deram à luz na MEAC-UFC entre os anos de 1992 e 2002 (seguimento médio de 15,2 anos). O grupo de exposição (GE) foi composto por 30 mulheres em qualquer categoria de SHG, e o grupo de não exposição (GNE) compreendeu 30 mulheres sem história de patologia obstétrica. Foram avaliados os dados antropométricos e laboratoriais associados ao risco cardiovascular e calculados o escore Framingham (variáveis dependentes). Para variáveis quantitativas, foram usados o teste $t$ de Student e o teste de Mann-Whitney. Para variáveis qualitativas, aplicou-se o teste exato de Fisher. Considerou-se a significância estatística como $\mathrm{p}<0,05$.

Resultados: GE apresentou valores mais altos de $\mathrm{IMC}(\mathrm{p}=0,03$, $\mathrm{OR}=1,13$, IC 1,00-1,3), PAS ( $\mathrm{p}=0,03, \mathrm{OR}=1,03$, IC 1,00-1,06), LDL-C ( $\mathrm{p}=0,02, \mathrm{OR}=1,02$, IC 1,00-1,04) e glicose de jejum $(\mathrm{p}=0,02, \mathrm{OR}=1,03$, IC $1,00-1,07)$, além de valores mais altos no escore de Framingham ( $\mathrm{p}=0,03, \mathrm{OR}=1,09$, IC 1,00-1,19). As mulheres em GE usaram medicamentos anti-hipertensivos com mais frequência ( $\mathrm{p}=0,03, \mathrm{OR}=5,2$, IC $1,3-21,2)$.

Conclusão: foi encontrado um perfil de risco cardiovascular desfavorável nas pacientes com história de SHG em comparação com as mulheres sem esse histórico.
Palavras-chave: pré-eclâmpsia; hipertensão induzida pela gravidez; doenças cardiovasculares; fatores de risco; epidemiologia.

\section{References}

1. Mansur AP, Favarato D. Mortalidade por doenças cardiovasculares no Brasil e na Região Metropolitana de São Paulo: Atualização 2011. Arq Bras Cardiol. 2012;99(2):755-61.

2. Hobel CJ, Arora CP. Cardiovascular disease risk factors for women. A life course-events perspective. Biopolymers and Cell. 2010;26(2):87-96.

3. Oliveira CA, Lins CP, Sá RAM, Chaves Netto H, Bornia RG, Silva NR, et al Síndromes hipertensivas da gestação e repercussões perinatais. Rev Bras Saúde Matern. Infant. 2006;6(1):93-8.

4. Kullima AA, Kawuwa B, Mohammed A, Hadiza U, Geidam AD. A 5-year review of maternal mortality associated with eclampsia in as tertiary institution of northern Nigéria. Ann Afric Med. 2009;8(2):81-4.

5. Canti ICT, Komlós M, Martins-Costa SH, Ramos JGL, Capp E, Corleta HVE. Risk factors for cardiovascular disease ten years after preeclampsia. São Paulo Med J. 2010;128(1):10-3.

6. Lykke JA, Langhoff-Roos J, Sibai BM, Funai EF. Hypertensive pregnancy disorders and subsequent cardiovascular morbidity and type 2 diabetes mellitus in the mother. Hypertension. 2009;53(6):944-95.

7. Wilson BJ, Watson MS, Prescott GJ, Sunderland S, Campbell DM, Hannaford $\mathrm{P}$, et al. Hypertensive diseases of pregnancy and risk of hypertension and stroke in later life: results from cohort study. BMJ. 2003;326(7394):845-9.

8. Hermes W, Franx A, Pampus MG, Bloemenkamp KW, Post J, Porath M, et al. Study protocol 10-Year cardiovascular event risks for women who experienced hypertensive disorders in late pregnancy: the HyRAS study. BMC Pregnancy Childbirth. 2010;10:28 AM.

9. Hermes W, Franx A, Pampus MGV, Bloemenkamp KWM, Bots ML, Post JAP, et al. Cardiovascular risk factors in women who had hypertensive disorders late in pregnancy: a cohort study. Am J Obstet Gynecol. 2013;208(6):474.

10. Sociedade Brasileira de Cardiologia. VI Diretrizes Brasileiras de Hipertensão. Arq Bras Cardiol. 2010;95(1 supl 1):1-51.

11. Sociedade Brasileira de Diabetes. Diretrizes da Sociedade Brasileira de Diabetes 2009. $3^{\text {a }}$ ed. Itapevi: Araújo Silva Farmacêutica; 2009.

12. Valdez R. A simple model-based index of abdominal adiposity. J Clin Epidemiol. 1991;44(9):955-6.

13. Brasil. Ministério da Saúde. Prevenção clínica de doenças cardiovasculares, cerebrovasculares e renais. Brasília (DF): Ministério da Saúde; 2006.

14. Sattar N, Greer IA. Pregnancy complications and maternal cardiovascular risk opportunities for intervention and screening? BMJ. 2002;325(7356):157-60.

15. Sesso HD, Lee IM, Gaziano M, Rexrode KM, Glynn RJ, Buring JE. Maternal and paternal history of myocardial infarction and risk of cardiovascular disease in men and women. Circulation. 2001;104(2):393-8.

16. Masson CR, Dias-da-Costa JS, Olinto MTA, Meneghel S, Costa CC, Bairros F, et al. Prevalência de sedentarismo nas mulheres adultas da cidade de São Leopoldo, Rio Grande do Sul, Brasil. Cad Saúde Pública. 2005;21(6):1685-94.

17. Callaway LK, Mcintyre D, Williams GM, Najman JM, Lawlor DA, Mamum A. Diagnosis and treatment of hypertension 21 years after a hypertensive; disorder of pregnancy. Aust N Z J Obstet Gynaecol. 2011;51(5):437-40.

18. Garovic VD, Bailey KR, Boerwinklec E, Hunt SC, Weder AB, Curb D, et al Hypertension in pregnancy as a risk factor for cardiovascular disease later in life. J Hypertens. 2010;28(4):826-33.

19. Wikstrom AK, Haglund B, Olovsson M, Lindeberg SN. The risk of maternal ischaemic heart disease after gestational hypertensive disease. BJOG 2005;112(11):1486-91.

20. Hartmann M, Dias-da-Costa JS, Olinto MTA, Pattussi MP, Tramontini A Prevalência de hipertensão arterial sistêmica e fatores associados: um estudo de base populacional em mulheres no Sul do Brasil. Cad Saúde Pública. 2007;23(8):1857-66.

21. Forest JC, Girouard I, Masse J, Moutquin JM, Kharfi A, Ness RB, et al. Early occurrence of metabolic syndrome after hypertension in pregnancy. Obstet Gynecol. 2005;105(6):1373-80. 
22. Cercato C, Mancini MC, Carvalho AM, Passos VQ, Villares SM, Halpern A. Systemic hypertension, diabetes mellitus, and dislipidemia in relation to body mass index: evaluation of a Brazilian population. Rev Hosp Clín Fac Med São Paulo. 2004;59(3):113-8.

23. Fraser A, Nelson SM, Macdonald-Wallis C, Cherry L, Butler E, Sattar N, et al. Association of pregnancy complications with calculated cardiovascular disease risk and cardiovascular risk factors in middle age: the Avon Longitudinal Study of Parents and Children. Circulation. 2012;125(11):1367-80.

24. Almeida RT, Almeida MMG, Araújo TM. Obesidade abdominal e risco cardiovascular: desempenho de indicadores antropométricos em mulheres. Arq Bras Cardiol. 2009;92(5):375-80.
25. Alberti KGMM, Zimmet P, Shaw J. Metabolic syndrome -- a new world-wide definition. A Consensus Statement from the International Diabetes Federation. Diabet Med. 2006;23(5):469-80.

26. Pitanga FJG, Lessa I. Indicadores antropométricos de obesidade como instrumento de triagem para risco coronariano elevado em adultos na cidade de Salvador (Bahia). Arq Bras Cardiol. 2005;85(1): 26-31.

27. Pitanga FJG, Lessa I. Razão cintura-estatura como discriminador do risco coronariano de adultos. Rev Assoc Med Bras. 2006;52(3):157-61.

28. Nakazone MA, Pinheiro A, Braile MCVB, Pinhel MAS, Sousa GF, Pinheiro Júnior S, et al. Prevalência de Síndrome Metabólica em indivíduos brasileiros pelos critérios de NCEP-ATPIII e IDF. Rev Assoc Med Bras. 2007;53(5):407-13. 